\title{
A CASE OF ATAXIA OF IRREgULAR TYPE FOLLOWING INJURY.
}

By F. X. DERCUM, M.D.,

Instructor in Nervous Diseases, University of Pennsylvania.

$I^{\mathrm{T}}$

$T$ is well recoynized that falls and blows upon the back, and, indeed, upon the body generally, stand not infrequently in a direct causal relation with disease of the cord. The resulting affection may be general as witness the occurrence of concussion myelitis, or, it may be limited to special tracts. In the latter instance, the tracts most frequently affected are the lateral columns, and we have gradually appearing the familar picture of a spastic paraplegia-a lateral sclerosis. Less often the posterior columns are involved, and we have the resulting picture as ataxia. As might, however, be expected on a priori grounds, the affection is apt to depart from the typical disease of the various columns. This is less noticeable in the case of spastic paraplegia, nore noticeable in the case of ataxia, as witness the following:

N. M., æt. 49, married, a German, and a dealer by occupation. Family history good. Alcoholism, syphilis or excessive venary denied. No history of any serious or longcontinued illness.

Nineteen years ago, while perfectly well, he was thrown from a wagon during a runaway, landing with the right side of his head against a curbstone and also badly bruising his body. He became unconscious, and remained so for eighteen hours. He was confined to bed for a week, partially recovered, and continued in indifferent health for some six months. During all of this time he suffered severely from headache. Finally be began decidedly to fail in general strength and to lose weight. This continued until a year after the accident, when he began to have severe stabbing pains in various parts of the body, notably in the arms and legs. About the same time he noticed that he would stagger while he walked, especially in the dark. These symp- 
toms persisted and in the following year-now two years after the accident-he began in addition to have convulsions. These invariably came on at night, appeared to be general, and recurred four or five times a month, and persisted with a somewhat lessened frequency up to the present time. At times he would wake up after the attack was over ; at times he would continue sleeping, knowing nothing of the convulsion except from the statements of his wife. Frequently passed his urine during a seizure.

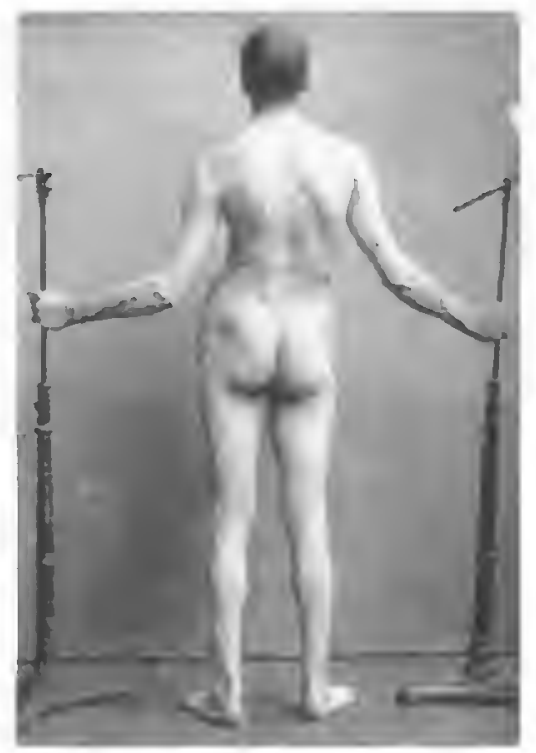

Posterior view showing lateral curvature and atrophy of left thigh.

The attack of pain in the arms and legs and over the trunk continued, though with somewhat lessened severity up to the present. The headache steadily persisted with little or no change in character. The unsteadiness in walking gradually increased until walking in the dark became very difficult, and even impossible.

Status Prescus.-Patient when standing sways considerably, and when eyes are closed will fall if not supported. Gait very ataxic. Knee-jerk absent on both sides. Sensation much delayed in both legs. Small patches of absolute anæsthesia about inner aspect of calves and 
ankles. Sensation also slightly impaired over hands and forearms. Temperature sense preserved.

As patient stands, decided wasting of the left thigh is noted, and is confirmed by measurement; the circumference of the right thigh, at the junction of the middle and upper thirds, is 18.5 inches, while that of the left at the same level is but I7. A slight difference is also detected in the calves, the right measuring $13^{1} /{ }_{4}$ and the left $\mathrm{I} 3$ inches. No difference is detected in the arms or forearms.

Marked scoliosis is also observed, the muscles of the back generally appearing to be weak and somewhat wasted, especially in the lower dorsal and lumbar regions, and more markedly upon the right side. This is well seen in the accompanying photographs. The trunk seen from behind is observed to curve markedly to the right, while viewed from the side it is also seen to sag very much forward.

Subjectively, the patient complains of great headache, which he refers to the site of the old head-injury. When carefully examined no decided irregularity or scar can be detected, though when compared with the opposite side, it appears a trifle flattened. It is further painful to pressure and percussion. Jabbing pains are still felt over arms and legs, though less than formerly. Patient has also a bandlike feeling about the abdomen.

No pain is elicited by pressure or percussion over the spine nor by transmitted shock through the head or shoulers. No tenderness is detected over the nerve trunks.

The eyes were now examined. Both pupils are large and react promptly to light and accommodation. Both nerves some what gray. Fields for red and green somewhat contracted. A detailed examination by Dr. C. A. Oliver is here appended :

\section{Ophthalmic Examination, September i8th, i89i,} By Charles A. Oliver.

Central vision for form in each eye normal. Accommodative range in each eye normal for age and refractive condition. Visual fields for red and green somewhat contracted in the left eye ; the red field of this eye showing a central negative scotoma of about twelve degrees in diameter, extending to about ten degrees to the nasal side of the fixation point - a similar scotoma crescentic in shape of about five degrees in length being situated about two degrees to the nasal side of the fixation point in the red field 
of the right eye. The area of green being about ten degrees concentrically smaller than the red field, gave negative fugitive scotoma, rapidly passing into positive fleeting ones at all and any portions of the fields. Pupils about three millimetres in horizontal meridians and irides freely mobile to light stimulus thrown binocularly and monocularly from all points of the visual field. (Curiously, the patient complained lately that " the light is too strong," he asserting that this has always been so.) Extra ocular muscle action, with the exception of a slight insufficiency of the interni, intact. Intraocular tension normal.

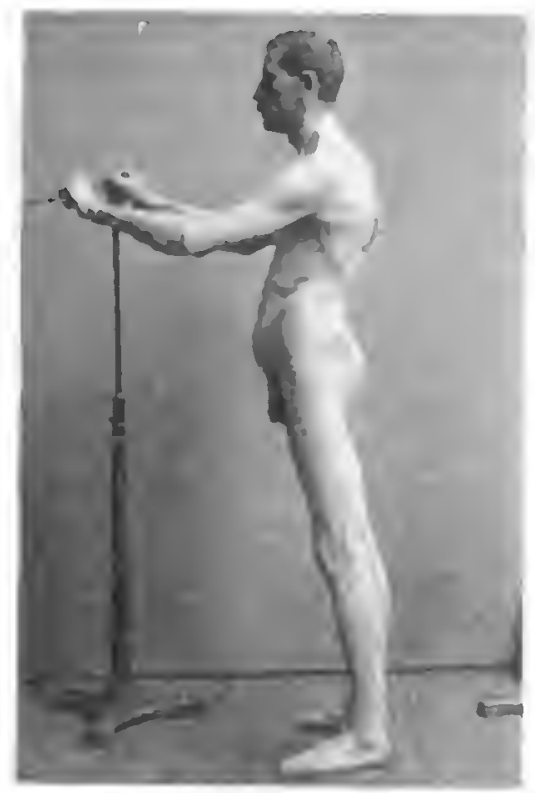

Lateral view showing weakness of back muscles and wasting of left thigh.

Ophthalmoscopically: No coarse changes in the choroid, retina and optic nerve, except a slight degeneration of the optic nerve tissue, more marked in the deeper layers and to the temporal side, this being more permanent in the left eye.

It will be noted from the above that the sides where we have the greatest anæsthesia for red correspond to the sides where the optic nerve degeneration is the most pronounced. 
Further than this, the fleeting scotomata for green in all portions of the field show impairment of the entire transverse diameter of the nerve trunk to the finer and more difficult transmissions.

The above case is especially interesting because of its etiology. The man was, as already stated, in good health at the time of the accident, and there was no history of any nervous disease in his family. There can be no doubt both on these grounds and on the grounds of the subsequent history that there was a causal relation between the injury and the ataxia. It is impossibie indeed to conclude otherwise.

That a slowly progressing degenerative lesion is here present must also be the case, but that it differs from the lesion of true locomotor ataxia, at least in the areas of the cord involved, is likewise evident, as witness the local muscular wastings. Secondly, the condition of the pupils is also a factor pointing in the same direction. The intense and constant headache bespeaks an organic cause again referrible to the trauma, while the associated epilepsy is very suggestive.

Why in one instance a trauma should result in a degeneration of the motor paths, and why in another of sensory tracts must remain a matter for speculation.

\section{HEMIHYPERTROPHY.}

Mobius (Muenchner med. Wochenshrift, 189, No. 44), reports the case of a boy fourteen years of age, whose parents were neurotic. The skull was symmetrical; the left cheek larger than the right. The left extremity in all parts were stouter and firmer than the right. Sensibility and reflexes were normal and equal upon both sides. The hypertrophy was looked upon as a pathological change. It is worthy of note that the vaso-motor disturbances of the skin were the greatest over those parts which were not hypertrophied.

W. M. L. 